\title{
Análise dos trabalhos sobre Química Quântica publicados nos anais do Encontro Nacional de Ensino de Química (ENEQ)
}

\author{
Henrique do N. Coutinho'(IC); Mariana R. dos Santos'(IC), Evelyn J. de L. Toledo'(PQ). \\ *henricoten@gmail.com \\ 'Laboratório de Pesquisas em Ensino de Química (LPEQ), Instituto de Química, Universidade de Brasília \\ (UnB), Brasília - DF
}

Palavras-Chave: Quântica, Revisão da Literatura, ENEQ

Resumo: Diante dA CRESCENTE PRESEnÇA da TEORIA QuÂNTICA No COTIDIANO DA SOCIEDADE ATUAL, ESSA PESQUISA TEM COMO OBJETIVO REALIZAR UMA REVISÃO DOS TRABALHOS SOBRE ENSINO DE QUíMICA QUÂNTICA NOS ANAIS DO ENEQ A FIM DE REFLETIR SOBRE PARTE DO PANORAMA DA PESQUISA NESSA ÁREA NO BRASIL E PROPOR DIRECIONAMENTOS PARA ESTUDOS FUTUROS. FOI REALIZADA UMA ANÁLISE DOS ANAIS DOS ENEQS REALIZADOS ENTRE 2006 E 2018 POR MEIO DO MÉTODO DE ANÁLISE DE CONTEÚDO INDICANDO QUE, DE FORMA GERAL, AINDA SÃO POUCOS OS TRABALHOS NESSA ÁREA E QUE ESSES SE CONCENTRAM EM PROPRIEDADES ATÔMICAS. MERECEM ESPECIAL ATENÇÃo DAS PESQUISAS FUTURAS A ÁREA DE FORMAÇÃo DE PROFESSORES PARA O ENSINO DE QUíMICA QUÂNTICA E O ENSINO DE PROPRIEDADES MOLECULARES SOB O PONTO DE VISTA QUÂNTICO, PREFERENCIALMENTE POR MEIO DO USO DE RECURSOS COMPUTACIONAIS. UMA POSSÍVEL FORMA DE SE ALCANÇAR ESSES OBJETIVOS É A REALIZAÇÃO DE PARCERIAS ENTRE PESQUISADORES DE QUíMICA QUÂNTICA E DE ENSINO DE QUÍMICA.

\section{INTRODUÇÃO}

A Teoria Quântica, cujos fundamentos foram lançados a cerca de um século, tem se mostrado essencial para a compreensão dos fenômenos em escala atômica e molecular e também, por extensão, essencial para a compreensão das diversas tecnologias neles baseadas, como a ressonância magnética, o laser, os semicondutores (base de todo o mundo digital) e muitas outras sem as quais o mundo moderno seria inimaginável.

O seu sucesso tem incentivado a associação do termo "quântico" aos mais diversos produtos e práticas como uma estratégia de marketing extremamente perversa que se aproveita da ignorância da população para obter lucros. Esse fenômeno, também conhecido por "misticismo quântico" consiste em atribuir uma conexão entre a consciência humana ou espiritualidade e os fenômenos quânticos. Essas interpretações estão inseridas na tradição do naturalismo animista (FREIRE JÚNIOR. et al., 2011). Não raro se veem anúncios de coachs quânticos, terapias quânticas, música quântica, energia quântica, sal quântico, etc.

Compreender os princípios dessa teoria, portanto, é fundamental para compreender o mundo em que vivemos. Assim, é tarefa da escola apresentá-los aos alunos de forma correta e compreensível, a fim de que eles se tornem cidadãos plenamente capazes de compreender a sua realidade e agir sobre ela, conforme preconiza a Lei de Diretrizes e Bases da Educação Nacional (LDB):

Art. 22. A educação básica tem por finalidades desenvolver o educando, assegurar-lhe a formação comum indispensável para o exercício da cidadania e 
fornecer-Ihe meios para progredir no trabalho e em estudos posteriores (BRASIL, 1996).

Devido às ferramentas matemáticas avançadas, como a resolução de equações diferenciais, e a algumas ideias contraintuitivas, como a dualidade onda-partícula e o princípio da incerteza, envolvidas nessa teoria, no entanto, muitas vezes ela é encarada como simplesmente incompreensível.

Essa visão, infelizmente, não é partilhada apenas pelos alunos da Educação Básica, mas também por muitos de seus professores, conforme apontado por Monteiro et al. (2009) ao analisarem o discurso de professores de Física de um município da região Nordeste.

Um bom ensino da Teoria Quântica, e mais especificamente da sua aplicação na Química, ou seja, da Química Quântica, depende, portanto, da realização de intensas pesquisas em formação de professores, desenvolvimento de materiais didáticos, uso de Tecnologias da Informação e Comunicação (TIC), entre tantas outras áreas do Ensino de Química.

Nesse contexto, trabalhos de revisão da literatura desempenham papel fundamental ao resumir os resultados obtidos pelos estudos realizados até então e, a partir da interpretação do conjunto desses resultados, propor um direcionamento para pesquisas futuras, conforme apontado por Figueiredo (1990).

O objetivo deste estudo, portanto, é fazer um levantamento dos trabalhos que abordam conceitos relacionados à Química Quântica, como quantização da energia, orbital, transição eletrônica e princípio da incerteza, nos anais do Encontro Nacional de Ensino de Química (ENEQ), o maior evento de Ensino de Química no país.

\section{MetOdOLOGiA}

Visando a compreender a forma como o ensino de questões relacionadas à Química Quântica têm sido abordado pela comunidade de Ensino de Química brasileira, realizamos uma análise dos anais do ENEQ por meio da metodologia de Análise de Conteúdo (BARDIN, 1977).

Inicialmente, fez-se uma busca, por meio da leitura dos títulos, de trabalhos (tanto trabalhos completos quanto resumos) que tratassem de conteúdos relacionados à Química Quântica nos anais dos ENEQs realizados entre 2006 e 2018, constituindo um total de sete edições do evento. Esse período foi escolhido devido à disponibilidade dos respectivos anais na internet, ou seja, a amostragem foi feita por conveniência (Oliveira, 2001).

Após essa busca inicial, realizou-se uma leitura flutuante dos trabalhos selecionados sem o uso de categorias pré-determinadas, de forma que elas surgiram ao longo da análise. Após a definição dessas categorias, realizou-se uma leitura mais aderente do material, de forma a extrair o máximo de informação possível.

\section{Resultados e Discussão}

Após a leitura dos anais dos ENEQs realizados entre 2006 e 2018, foi encontrado um total de 19 trabalhos que tratam de conteúdos relacionados à Química Quântica. $A$ distribuição desses trabalhos por edição do evento está representada na Figura 1. 


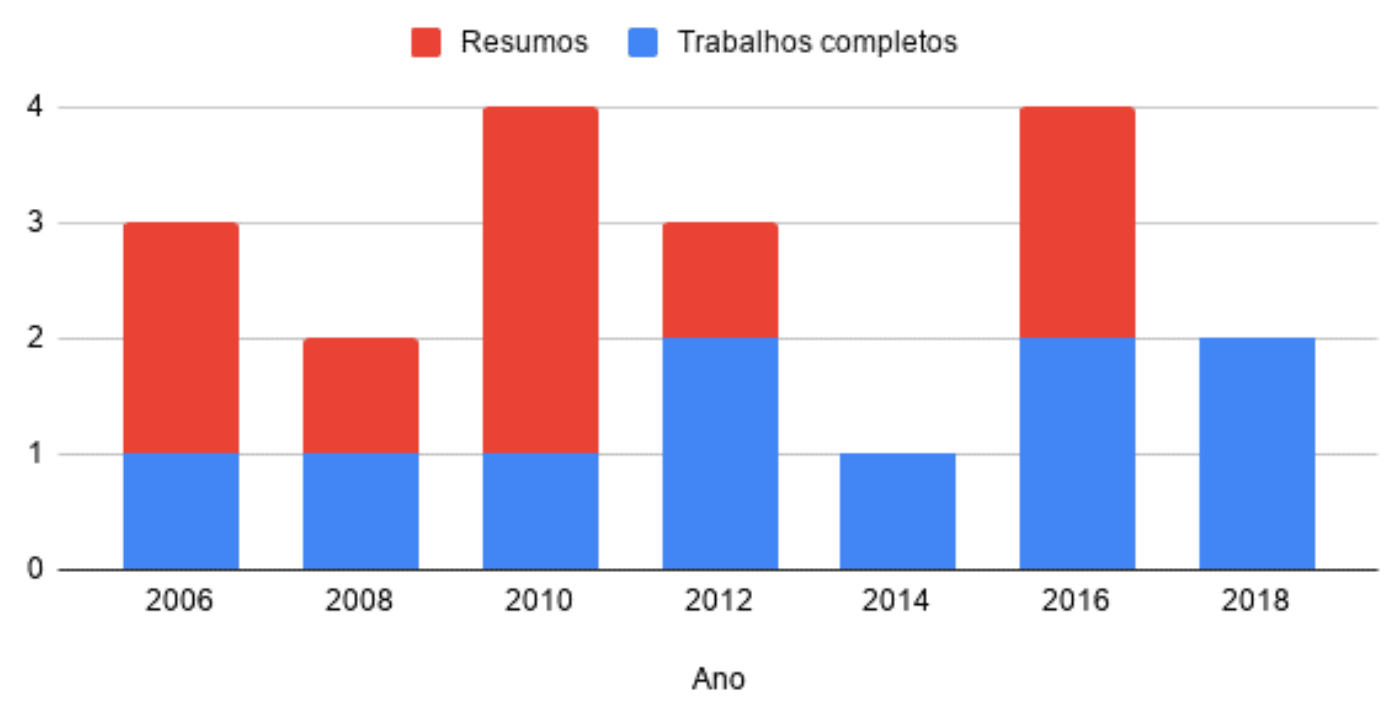

Figura 1: Trabalhos relacionados à Química Quântica por ano localizados nos anais do ENEQ

Por meio da análise do gráfico, percebe-se que a quantidade de trabalhos sobre o tema é muito pequena, principalmente se levarmos em conta sua porcentagem em relação ao todo. Na XVIII edição (ENEQ 2016), por exemplo, os quatro trabalhos relacionados à Quântica representam apenas cerca de 0,3\% dos 1458 publicados. Além disso, quase metade dos trabalhos encontrados (9 do total de 19) são resumos, os quais, devido à limitação de espaço, costumam contribuir muito pouco para a consolidação dessa importante área de pesquisa.

A análise de conteúdo desses trabalhos revelou que eles podem ser subdivididos, de acordo com a forma como abordam o tema, nas seguintes categorias: "análise de percepções dos alunos", "análise de livros", "análise de conceitos", "história e filosofia da ciência" e "atividades experimentais", conforme indicado no Quadro 1.

\section{Quadro 1: Trabalhos relacionados à Química Quântica localizados nos anais do ENEQ e suas categorias}

\begin{tabular}{|c|c|c|c|}
\hline TÍTULO & AUTOR & CATEGORIA & ANO \\
\hline $\begin{array}{l}\text { Alunos aprendendo com alunos: } \\
\text { Uma experiência para introdução à } \\
\text { Química Quântica }\end{array}$ & $\begin{array}{l}\text { Pedro Vieira Neto de Rolan } \\
\text { Teixeira (IC), William Millani } \\
\text { (IC), Santiago Francisco Yunes } \\
\text { (PQ) }\end{array}$ & $\begin{array}{c}\text { Atividades } \\
\text { experimentais }\end{array}$ & 2010 \\
\hline $\begin{array}{l}\text { Quântica: uma Abordagem } \\
\text { Problematizadora no Ensino } \\
\text { integrando a Química e a Física } \\
\text { para alunos do CEEBJA }\end{array}$ & $\begin{array}{c}\text { Elizabete Silva Pires (FM), } \\
\text { Emília Emiko Irikuchi (FM), } \\
\text { Janete Duarte Rogoski (FM), } \\
\text { Rogério Bergantin Brasil (FM), } \\
\text { Vilma Biadola (FM) }\end{array}$ & $\begin{array}{l}\text { Atividades } \\
\text { experimentais }\end{array}$ & 2010 \\
\hline $\begin{array}{c}\text { Ensinando Orbitais Utilizando Bolas } \\
\text { de Isopor }\end{array}$ & $\begin{array}{c}\text { Cledson Pereira Mota } \\
\text { (IC), Adriano José de Oliveira } \\
\text { (FM) e Márlon H. F. B. Soares } \\
\text { (PQ). }\end{array}$ & $\begin{array}{c}\text { Atividades } \\
\text { experimentais }\end{array}$ & 2006 \\
\hline $\begin{array}{l}\text { Entendendo o salto quântico: uma } \\
\text { maneira colorida de aprender com } \\
\text { um experimento de baixo custo. }\end{array}$ & $\begin{array}{c}\text { Thalita J. Albeza } \\
\text { (IC), Ana C. I. de Souza (IC), } \\
\text { Juliana B. Galvão (IC), Wagner } \\
\text { A. Moreira (PQ) }\end{array}$ & $\begin{array}{l}\text { Atividades } \\
\text { experimentais }\end{array}$ & 2006 \\
\hline
\end{tabular}




\begin{tabular}{|c|c|c|c|}
\hline $\begin{array}{c}\text { Atividade Interativa de Saltos } \\
\text { Quânticos }\end{array}$ & $\begin{array}{c}\text { Ana Maria Coulon Grisa (PQ), } \\
\text { Maria Alice Reis Pacheco (PQ), } \\
\text { Helena Libardi (PQ), Valquiria } \\
\text { Villas-Boas (PQ), Juliana } \\
\text { Brunetto (IC) }\end{array}$ & $\begin{array}{l}\text { Atividades } \\
\text { experimentais }\end{array}$ & 2006 \\
\hline $\begin{array}{l}\text { Obstáculos epistemológicos: O } \\
\text { conceito de Quantização de } \\
\text { energia nos livros didáticos de } \\
\text { química do ensino médio }\end{array}$ & $\begin{array}{c}\text { Marcos Antonio Sousa Barros } \\
\text { (PG) }\end{array}$ & $\begin{array}{l}\text { Análise de } \\
\text { livros }\end{array}$ & 2010 \\
\hline $\begin{array}{l}\text { O conceito de orbital em livros } \\
\text { didáticos de química geral para o } \\
\text { Ensino Superior no século XX }\end{array}$ & $\begin{array}{c}\text { Evandro F. Rozentalski (PG), } \\
\text { Paulo A. Porto (PQ) }\end{array}$ & $\begin{array}{l}\text { Análise de } \\
\text { livros }\end{array}$ & 2012 \\
\hline $\begin{array}{c}\text { Modelo quântico do átomo: uma } \\
\text { análise do ensino das noções de } \\
\text { quantum de uma grandeza e } \\
\text { comportamento dual da energia e } \\
\text { da matéria }\end{array}$ & $\begin{array}{l}\text { Lucilene Correia Ramos (IC), } \\
\text { José Luis P. B. Silva (PQ) }\end{array}$ & $\begin{array}{l}\text { Análise de } \\
\text { livros }\end{array}$ & 2012 \\
\hline $\begin{array}{c}\text { Números quânticos: evolução ou } \\
\text { involução do conteúdo nos livros } \\
\text { didáticos }\end{array}$ & $\begin{array}{l}\text { Thiago S. Castro (IC), Eduardo } \\
\text { Luiz Dias Cavalcante (PQ) }\end{array}$ & $\begin{array}{l}\text { Análise de } \\
\text { livros }\end{array}$ & 2016 \\
\hline $\begin{array}{l}\text { Descrição Física da Realidade e o } \\
\text { Princípio de Incerteza: livros } \\
\text { didáticos e vieses filosóficos }\end{array}$ & $\begin{array}{c}\text { José Bento Suart Júnior (PG) } \\
\text { Sílvia Regina Quijadas Aro } \\
\text { Zuliani (PQ) }\end{array}$ & $\begin{array}{l}\text { Análise de } \\
\text { livros }\end{array}$ & 2010 \\
\hline $\begin{array}{l}\text { O elétron rotatório e o spin do } \\
\text { elétron no Ensino de Química }\end{array}$ & $\begin{array}{c}\text { Joel A. M. Porto (IC), José Luis } \\
\text { P. B. Silva (PQ). }\end{array}$ & $\begin{array}{l}\text { História e } \\
\text { Filosofia da } \\
\text { Ciência }\end{array}$ & 2016 \\
\hline $\begin{array}{c}\text { O sistema conceitual dos números } \\
\text { quânticos }\end{array}$ & $\begin{array}{l}\text { Juliel Cerqueira da Silva (PG), } \\
\text { José Luis P. B. Silva (PQ). }\end{array}$ & $\begin{array}{l}\text { História e } \\
\text { Filosofia da } \\
\text { Ciência }\end{array}$ & 2016 \\
\hline $\begin{array}{l}\text { Diagrama de Linus Pauling: } \\
\text { controvérsias entre os } \\
\text { conhecimentos científico e escolar }\end{array}$ & $\begin{array}{l}\text { André Gonçalves Amaral Bianco } \\
\text { (PQ), Reginaldo Alberto Meloni } \\
\text { (PQ) }\end{array}$ & $\begin{array}{l}\text { História e } \\
\text { Filosofia da } \\
\text { Ciência }\end{array}$ & 2018 \\
\hline $\begin{array}{l}\text { Ligação Covalente: Modelo } \\
\text { Clássico ou Quântico? }\end{array}$ & Uarison Rodrigues Barreto (PG) & $\begin{array}{l}\text { História e } \\
\text { Filosofia da } \\
\text { Ciência }\end{array}$ & 2018 \\
\hline $\begin{array}{l}\text { Para compreender o modelo } \\
\text { atômico quântico }\end{array}$ & $\begin{array}{c}\text { José Luis P. B. Silva (PQ), } \\
\text { Maria Bernadete de Melo Cunha } \\
\text { (PQ) }\end{array}$ & $\begin{array}{l}\text { Análise de } \\
\text { conceitos }\end{array}$ & 2008 \\
\hline $\begin{array}{l}\text { Um sistema de conceitos para o } \\
\text { ensino de orbital atômico. }\end{array}$ & $\begin{array}{l}\text { Márcio Matos Lima (IC), José } \\
\text { Luis P.B.Silva (PQ) }\end{array}$ & $\begin{array}{l}\text { Análise de } \\
\text { conceitos }\end{array}$ & 2016 \\
\hline $\begin{array}{c}\text { O Que é a Incerteza? Reflexões } \\
\text { sobre o Ensino e Aprendizagem de } \\
\text { Conceitos, no Desenvolvimento de } \\
\text { uma Estratégia de Ensino }\end{array}$ & $\begin{array}{c}\text { José Bento Suart Júnior (IC), } \\
\text { Sílvia Regina Quijadas Aro } \\
\text { Zuliani (PQ) }\end{array}$ & $\begin{array}{l}\text { Análise de } \\
\text { conceitos }\end{array}$ & 2008 \\
\hline $\begin{array}{c}\text { Sobre o Ensino de Números } \\
\text { Quânticos }\end{array}$ & $\begin{array}{l}\text { Juliel Cerqueira da Silva (IC), } \\
\text { José Luis P.B.Silva (PQ). }\end{array}$ & $\begin{array}{l}\text { Análise de } \\
\text { conceitos }\end{array}$ & 2014 \\
\hline
\end{tabular}




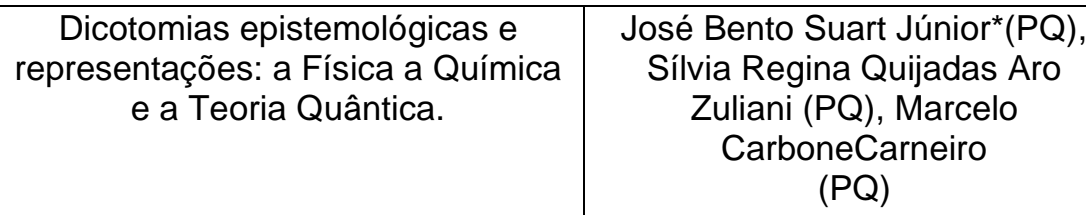

A classe de "análise de percepção dos alunos", diferentemente das demais, é constituída de um único trabalho, o qual emprega um pequeno questionário com duas questões abertas para tentar compreender como os alunos de licenciatura em Física e Química tratam o átomo e a ligação química. Como resultado, extremamente preocupante, Suart Júnior et al. (2012) apontam que os cursos desses alunos não foram capazes de promover neles uma compreensão melhor desses conceitos do que aquela apresentada por alunos do Ensino Médio.

O trabalho foi realizado com alunos de apenas uma instituição de ensino, o que indica a necessidade de se realizar estudos semelhantes em outras realidades. Supondo, no entanto, que a observação reflita a situação geral dos cursos de formação de professores no país, ela pode ajudar a explicar o porquê de termos tão poucos trabalhos na área de Ensino de Química Quântica nos anais do maior evento de Ensino de Química do Brasil. Situação essa ainda mais preocupante quando consideramos a filiação dos autores principais desses poucos trabalhos localizados nos anais conforme indicado na Figura 2.

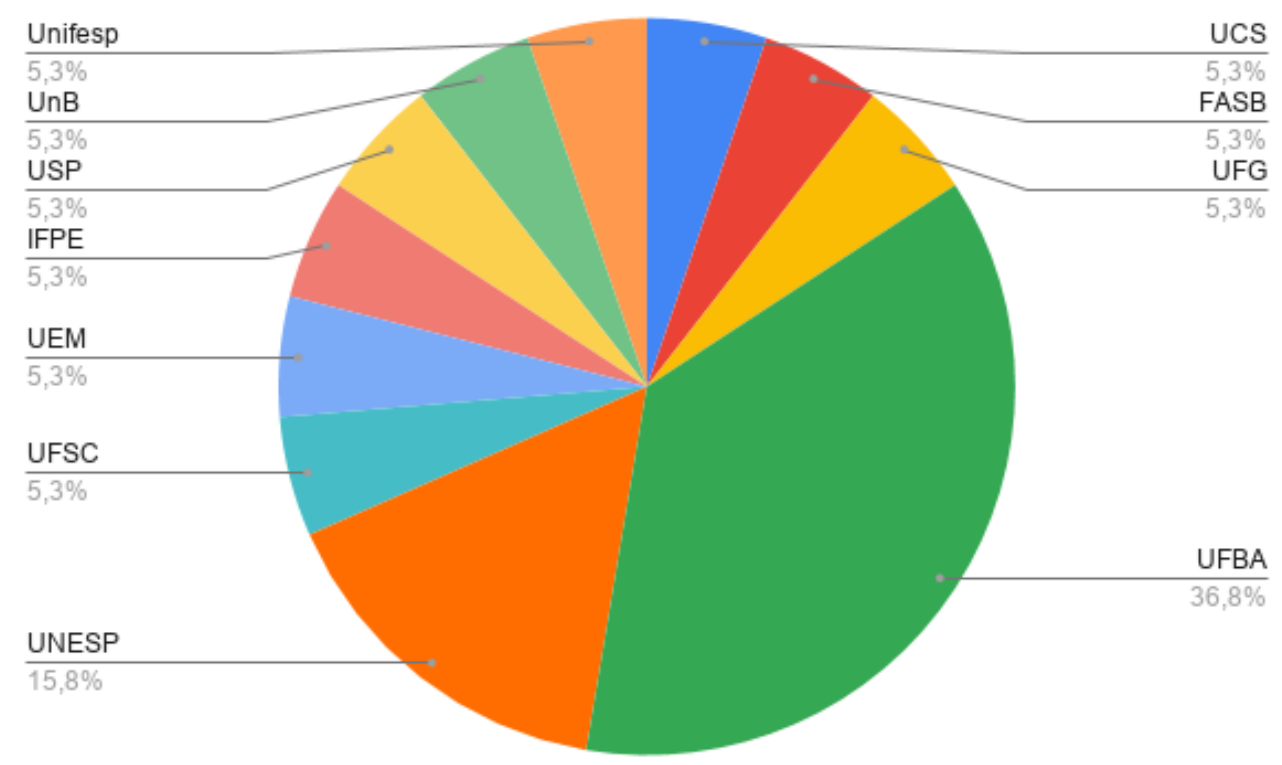

Figura 2: Trabalhos relacionados a Química Quântica por Instituição de Ensino

A predominância de instituições de ensino públicas (apenas um dos 19 trabalhos foi desenvolvido por autores vinculados a uma faculdade particular) já era esperada, dado que cerca de $90 \%$ da produção científica brasileira é proveniente das universidades públicas (HILU; GISI, 2011). A enorme concentração de trabalhos em apenas duas instituições, no entanto, chama bastante a atenção. A Universidade Federal da Bahia (UFBA), em especial, concentra mais de um terço dos trabalhos.

Isso pode ser entendido se analisarmos a formação do pesquisador envolvido (seja como autor ou como coautor) em 6 dos 7 trabalhos vinculados a essa instituição 
de ensino, o qual fez intenso uso dos princípios da Química Quântica em seu doutorado em Química Orgânica.

Tomando esse caso como exemplo, uma das formas de se produzir mais trabalhos de qualidade na área de Ensino de Química Quântica poderia ser a realização de parcerias entre pesquisadores da Química Quântica e do Ensino de Química, haja vista que um dos grupos possui o conhecimento dos conceitos a serem abordados e o outro da forma como essa abordagem deve ser feita.

A UNESP, por sua vez, embora não se destaque tanto quanto a UFBA, apresenta três vezes mais trabalhos do que as demais instituições. Nesse caso, o autor principal de todos os trabalhos vem se dedicando ao estudo do Ensino de Quântica desde a graduação. Tanto é que seu trabalho de conclusão de curso, sua dissertação e boa parte de suas publicações em revistas e congressos foram relacionados a essa temática.

Os demais autores, por outro lado, apoiados apenas no que lhes foi ensinado na graduação e em estudos próprios, talvez não se sintam à vontade para tratar do assunto e publicaram apenas uma vez, dificultando a continuidade e aprofundamento das pesquisas na área.

Ademais, uma investigação pertinente seria a estrutura do currículo dos cursos de licenciatura, verificando se há presença do conteúdo de Química Quântica e, se há, em que momento ele aparece e em quantas vezes ao longo do fluxo de disciplinas obrigatórias. Além disso, é importante analisar a(s) ementa da(s) disciplina(s) a fim de constatar se o foco é a resolução matemática ou as questões conceituais.

Ainda que não se sintam à vontade para tratar do assunto em profundidade, muitos professores da Educação Básica, e mesmo do Ensino Superior, se veem obrigados a ensinar princípios de Química Quântica em sala de aula para cumprir os programas das instituições de ensino das quais fazem parte. Diante dessa situação, cresce a importância dos livros didáticos, conforme apontado por Carneiro et al. (2005):

Apesar dos avanços tecnológicos e da enorme variedade de materiais curriculares, atualmente disponíveis no mercado, o livro didático, LD, continua sendo o recurso mais utilizado no ensino de ciências. Essa centralidade lhe confere estatuto e funções privilegiadas na medida em que é através dele que o professor organiza, desenvolve e avalia seu trabalho pedagógico de sala de aula (Carneiro et al. 2005, p. 2).

Trabalhos de "análise de livros", portanto, são essenciais para melhorar o ensino desses conceitos. Dentre os trabalhos analisados, 5 se encaixam nessa categoria sendo 2 voltados para o Ensino Superior, um tratando do conceito de orbital e outro das implicações filosóficas do Princípio da Incerteza, e 3 para o Ensino Médio, tratando dos conceitos de quantização, de caráter dual e de números quânticos.

De forma geral, esses trabalhos apontam que a forma como os conceitos de Química Quântica são tratados está longe de ser ideal, o que também pode ser reflexo das deficiências na formação de professores nessa área Ramos e Silva (2012), por exemplo, ao analisarem os livros de Química do PNLD 2012 apontam que tais conceitos raramente são tratados fora do primeiro volume das coleções, que é o volume onde se trata de atomística. Mesmo quando eles são tratados em vários momentos, nunca são utilizados de forma articulada para explicar conceitos como a formação de ligações químicas, as quais só são plenamente compreendidas utilizando-se teorias baseadas em princípios quânticos, a saber, a Teoria da Ligação de Valência e, mais recentemente, a Teoria do Orbital Molecular. 
Mesmo entre os livros voltados para o Ensino Superior, foram encontrados problemas na abordagem desses conceitos, embora de uma natureza diferente daquela encontrada nos livros do Ensino Médio. No caso do Ensino Superior, os problemas encontrados estão relacionados principalmente aos significados atribuídos a esses conceitos, em especial o conceito de orbital (ROZENTALSKI; PORTO, 2012) e o do princípio da incerteza (SUART JÚNIOR; ZULIANI, 2010).

É interessante notar que não apenas os livros didáticos apresentam problemas na forma como tratam os conceitos de Química Quântica, mas também os próprios trabalhos aqui analisados. Em nenhum momento faz-se referência a transições eletrônicas, mas sim a "saltos quânticos", termo esse que pode dar ideia de que os níveis de energia no átomo possuem uma existência física palpável. Essa questão foi levantada apenas por Barros (2010) ao analisar possíveis obstáculos epistemológicos em livros de Química do Ensino Médio. Esse fato é mais um indicativo da possível deficiência na formação dos professores em relação a esse assunto e, portanto, reforça a necessidade de se realizar pesquisas mais aprofundadas no futuro.

E não apenas a forma, como os conceitos de Química Quântica costumam ser abordados, é insatisfatória, como também não parece caminhar no sentido de vir a ser, mas sim estar estagnada no mesmo patamar de décadas atrás. Em alguns casos, podese dizer até mesmo que houve um retrocesso, haja vista a redução da presença desses conceitos em certas obras.

Nesse sentido, merece atenção especial o trabalho de Castro e Cavalcanti (2016) sobre a evolução nas formas de se ensinar números quânticos empregadas em livros didáticos de Ensino Médio publicados entre 1960 e 2015, o qual aponta que "felizmente" a presença desse conteúdo tem diminuído nos últimos anos. A justificativa para celebrar a retirada dos números quânticos em alguns livros didáticos e recomendála nos demais é a complexidade supostamente alta demais para alunos do Ensino Médio e o fato de que o conceito não é apresentado de forma correta e, portanto, melhor seria nem mesmo apresentá-lo.

$\mathrm{Na}$ contramão desse estudo, há um outro, na classe de "análise de conceitos", que defende justamente o contrário, ou seja, que os números quânticos devem sim ser ensinados no Ensino Médio. De acordo com Silva e Silva (2014), os números quânticos são parte integrante do modelo atômico atual, essencial para explicar adequadamente vários fenômenos do dia-a-dia, como as cores dos objetos, e, portanto, devem sim ser ensinados, ainda que a sua completa compreensão dependa de uma base matemática inexistente entre os alunos do Ensino Médio.

Os demais trabalhos dessa classe (dois trabalhos completos e um resumo) buscam desenvolver um arcabouço teórico em torno dos conceitos de orbital atômico, modelo atômico quântico e princípio da incerteza. Mesmo os trabalhos completos, no entanto, representam, no máximo, uma introdução ao tema.

Um estudo mais aprofundado pode ser empreendido pelos interessados por meio da leitura dos artigos originais referenciados nos trabalhos da classe que trata da "história e filosofia da ciência". Nessa classe encontramos dois resumos e dois trabalhos completos, os quais tratam de números quânticos, spin eletrônico, ligação química e diagrama de Linus Pauling para distribuição eletrônica.

Por fim, na classe das "atividades experimentais", temos 4 resumos e apenas um trabalho completo. Evidentemente, isso leva a uma falta de detalhamento das propostas, o que dificulta a sua reprodução. Além disso, três das cinco propostas se baseiam num mesmo experimento, o teste da chama, e nenhuma delas afirma ter empregado algum tipo de instrumento de análise para determinar o efeito da atividade 
experimental sobre o aprendizado dos alunos, apenas observaram que os alunos ficaram "interessados".

Albeza et al. (2006, p. 1), por exemplo, afirma que “(...) uma demonstração experimental envolvendo chamas desperta a curiosidade, o interesse e prende a atenção dos alunos." A questão não é se um "experimento com chamas" chama a atenção dos alunos, isso é inegável. O verdadeiro ponto é se essa atenção se reflete em aprendizado dos conceitos abordados, no caso o de transição eletrônica, ou se o aluno simplesmente se prende ao fenômeno macroscópico, constituindo o que Bachelard (1996) chamou de obstáculo da experiência primeira.

Ainda na classe das "atividades experimentais", merece destaque o estudo de Mota et al. (2006), no qual bolas de isopor foram utilizadas para representar os orbitais atômicos. Esse tipo de atividade deve ser realizada com muito cuidado para não dar aos alunos a impressão de que o orbital (seja ele atômico ou molecular) possui uma forma física palpável, mas sim que ele é uma região do espaço onde a probabilidade de se encontrar os elétrons a ele atribuídos é grande.

Talvez uma forma mais adequada de se abordar esse tema fosse o uso de softwares de modelagem molecular, os quais, a despeito do crescente uso das TIC no Ensino de Ciências apontado por Reis et al. (2017), não foram empregados em nenhum dos trabalhos aqui analisados. Essas ferramentas poderiam, inclusive, auxiliar na transição entre o estudo de propriedades atômicas, tema da maioria dos trabalhos aqui analisados, e o estudo de propriedades moleculares, abordadas por apenas dois dos dezenove trabalhos, haja vista que a aplicação da Mecânica Quântica a sistemas reais hoje demanda, invariavelmente, o uso de recursos computacionais.

Mais do que isso: o uso de softwares de modelagem molecular e outros softwares relacionados pode contribuir para o desenvolvimento da competência geral número 5 da Base Nacional Comum Curricular (BNCC):

5. Compreender, utilizar e criar tecnologias digitais de informação e comunicação de forma crítica, significativa, reflexiva e ética nas diversas práticas sociais (incluindo as escolares) para se comunicar, acessar e disseminar informações, produzir conhecimentos, resolver problemas e exercer protagonismo e autoria na vida pessoal e coletiva. (BRASIL, 2017, p. 9).

O espaço disponível para novas pesquisas na área, portanto, é vasto e muito ainda tem que ser feito para que o ensino de conteúdos de Química Quântica alcance plenamente o seu papel de participar na formação de cidadãos com espírito crítico, conforme apontado por Silva e Silva (2014).

\section{Conclusão}

A análise de conteúdo dos anais do ENEQ de 2006 a 2018 resultou em apenas 19 trabalhos sobre Ensino de Química Quântica, os quais foram subdivididos em cinco categorias: "análise de percepções dos alunos", "análise de livros", "análise de conceitos", "história e filosofia da ciência" e "atividades experimentais". Isso indica a necessidade de uma maior quantidade de estudos nessas e também em outras categorias relacionadas a esse tema.

O trabalho da categoria de "análise de percepções dos alunos" indica que o Ensino da Teoria Quântica em cursos de formação de professores de Química e Física está longe do ideal. Isso pode ser associado tanto às inadequações encontradas em 
livros didáticos que tratam do assunto, conforme apontado pelos trabalhos de "análise de livros" quanto à própria escassez de trabalhos científicos na área nos anais do ENEQ.

Nesse sentido, um estudo dos trabalhos sobre "análise de conceitos" em associação com os artigos originais utilizados como referência nos trabalhos de "história e filosofia da ciência" pode ser uma boa forma de tentar reduzir essas deficiências da formação. Isso, no entanto, certamente não exime a comunidade brasileira de Ensino de Química de empreender novos e mais aprofundados estudos na área de formação de professores para o Ensino de Química Quântica.

Em relação ao uso de "atividades experimentais", percebe-se a necessidade de se estudar uma maior variedade de atividades para se trabalhar os conceitos de Química Quântica, haja vista que mais da metade dos trabalhos analisados faz uso do mesmo experimento, o teste da chama. Destaque especial deve ser dado para o uso de recursos computacionais, não explorados por nenhum dos trabalhos aqui analisados. Vale ressaltar, também, que essas atividades devem ser planejadas e executadas com todo o cuidado, de forma a realmente facilitar o aprendizado dos conceitos e não promover obstáculos epistemológicos.

Por fim, destaca-se a necessidade de se trabalhar não apenas propriedades atômicas, mas também propriedades moleculares sob um ponto de vista Quântico, pois essas propriedades são essenciais para a compreensão do mundo moderno e seus fenômenos. Isso certamente só poderá ser feito a contento por meio da realização de uma série de estudos na área, os quais podem ser muito beneficiados pela realização de parcerias entre pesquisadores de Ensino de Química e de Química Quântica.

\section{AgRADECIMENTOS}

Universidade de Brasília. PET - QUI/UnB. PET/SeSU/MEC.

\section{REFERÊNCIAS}

ALBEZA, T. J.; SOUZA, A. C. I.; GALVÃO, J. B.; MOREIRA, W. A. Entendendo o salto quântico: uma maneira colorida de aprender com um experimento de baixo custo. In: Encontro Nacional de Ensino de Química, 13., 2006, Campinas. Anais ... Campinas: ENEQ, 2006. Disponível em: http://www.sbq.org.br/ensino/ eneq. Acesso em: 19 jul. 2020 .

BACHELARD, Gaston. A formação do espírito científico: contribuição para uma psicanálise do conhecimento. Rio de Janeiro: Contraponto, 1996. 316 p.

BARDIN, Laurence. Análise de conteúdo. Lisboa: Edições 70,1977. 225 p.

BARRETO, U. R. Ligação Covalente: Modelo Clássico ou Quântico? In: Encontro Nacional de Ensino de Química, 19., 2018, Rio Branco. Anais ... Rio Branco: ENEQ, 2018. p. 1051-1062. Disponível em:

https://www.eneq2018noacre.com.br/conteudo/view?ID CONTEUDO=421. Acesso em: 19 jul. 2020. 
BARROS, M. A. S. Obstáculos epistemológicos: O conceito de Quantização de energia nos livros didáticos de química do ensino médio. In: Encontro Nacional de Ensino de Química, 15., 2010, Brasília. Anais ... Brasília: ENEQ, 2010. Disponível em: http://www.sbq.org.br/eneq/xv/resumos/R1199-1.pdf. Acesso em: 19 jul. 2020.

BIANCO, A. G. A.; MELONI, R. A. Diagrama de Linus Pauling: controvérsias entre os conhecimentos científico e escolar. In: Encontro Nacional de Ensino de Química, 19., 2018, Rio Branco. Anais... Rio Branco: ENEQ, 2018. p. 1843-1853. Disponível em: https://www.eneq2018noacre.com.br/conteudo/view?ID CONTEUDO=421. Acesso em: 19 jul. 2020.

BRASIL. Base Nacional Comum Curricular (BNCC). Educação é a Base. Brasília, MEC/CONSED/UNDIME, 2017.

BRASIL. Lei de Diretrizes e Bases da Educação Nacional, LDB. 9394/1996.

CARNEIRO, Maria. H. da S.; SANTOS, Wildson. L. P. dos; MÓL, Gerson. de S. Livro didático inovador e professores: uma tensão a ser vencida. Ensaio-Pesquisa em Educação em Ciências, Belo Horizonte, v. 7, n. 2, p. 101-113, 2005. Disponível em: https://www.scielo.br/pdf/epec/v7n2/1983-2117-epec-7-02-00101.pdf. Acesso em: 19 jul. 2020.

CASTRO, T. S; CAVALCANTI, E. L. D. NÚMEROS QUÂNTICOS: evolução ou involução do conteúdo nos livros didáticos. In: Encontro Nacional de Ensino de Química, 18., 2016, Florianópolis. Anais... Florianópolis: ENEQ, 2016. Disponível em: http://www.eneq2016.ufsc.br/anais/resumos/R1687-1.pdf. Acesso em: 19 jul. 2020.

FIGUEIREDO, Nice. Da importância dos artigos de revisão da literatura. Revista Brasileira de Biblioteconomia e Documentação, São Paulo, v. 23, n. 1, p. 131-135, 1990. Disponível em:

https://brapci.inf.br/ repositorio/2011/09/pdf 6245ece57c 0018790.pdf. Acesso em: 19 jul. 2020.

FREIRE JÚNIOR, O.; PESSOA JÚNIOR, O.; BROMBERG, J. L. (orgs). Teoria Quântica: estudos históricos e implicações culturais. Campina Grande: EDUEPB; São Paulo: Livraria da Física, 2011. Disponível em: http://books.scielo.org/id/xwhf5. Acesso em: 19 jul. 2020.

GRISA, A. M. C.; PACHECO, M. A. R.; LIBARDI, H.; VILLASBOAS, V.; BRUNETTO, J. Atividade Interativa de Saltos quânticos. In: Encontro Nacional de Ensino de Química, 13., 2006, Campinas. Anais... Campinas: ENEQ, 2006. Disponível em: http://www.sbq.org.br/ensino/ eneq. Acesso em: 19 jul. 2020.

HILU, Luciane; GISI, Maria L. Produção Científica no Brasil: um comparativo entre as universidades públicas e privadas. In: Congresso Nacional de Educação, 10.;

Seminário Internacional de Representações Sociais, Subjetividade e Educação, 1., 2011, Curitiba. Anais... Curitiba: EDUCERE/ SIRSSE, 2011, p. 5664-5672. Disponível em: https://educere.bruc.com.br/arquivo/pdf2011/5221 3061.pdf. Acesso em: 19 jul. 2020. 
LIMA, M. M.; SILVA, J. L. P. B. Um sistema de conceitos para o ensino de orbital atômico. In: Encontro Nacional de Ensino de Química, 18., 2016, Florianópolis. Anais ... Florianópolis: ENEQ, 2016. Disponível em: http://www.eneq2016.ufsc.br/anais/resumos/R1281-1.pdf. Acesso em: 19 jul. 2020.

MONTEIRO, Maria A.; NARDI, Roberto; BASTOS FILHO, Jenner B. A sistemática incompreensão da teoria quântica e as dificuldades dos professores na introdução da Física Moderna e Contemporânea no Ensino Médio. Ciência \& Educação. (Bauru), Bauru, v. 15, n. 3, p. 557-580, 2009. Disponível em: https://www.scielo.br/pdf/ciedu/v15n3/07.pdf. Acesso em: 19 jul. 2020.

MOTA, C. P.; OLIVEIRA, A. J.; SOARES, M. H. F. B. Ensinando Orbitais Utilizando Bolas de Isopor. In: Encontro Nacional de Ensino de Química, 13., 2006, Campinas. Anais. Campinas: ENEQ, 2006. Disponível em: http://www.sbq.org.br/ensino/ eneq. Acesso em: 19 jul. 2020.

OLIVEIRA, Tânia M. V. Amostragem não probabilística: adequação de situações para uso e limitações de amostras por conveniência, julgamento e cotas. Rev Adm On Line, v. 2, n. 3, 2001. Disponível em: https://pesquisaeaesp.fgv.br/sites/gvpesquisa.fgv.br/files/arquivos/veludo amostragem nao probabilistica adequacao de situacoes para uso e limitacoes d e amostras por conveniencia.pdf. Acesso em 19 jul. 2020.

PIRES, E., S.; IRIKUCHI, E. E.; ROGOSKI, J. D.; BRASIL, R. B.; BIADOLA, V. Quântica: uma Abordagem Problematizadora no Ensino integrando a Química e a Física para alunos do CEEBJA. In: Encontro Nacional de Ensino de Química, 15., 2010, Brasília. Anais... Brasília: ENEQ, 2010. Disponível em: http://www.sbq.org.br/eneq/xv/resumos/R0945-1.pdf. Acesso em: 19 jul. 2020.

PORTO, J. A. M.; SILVA, J. L. P. B. O elétron rotatório e o spin do elétron no ensino de química. In: Encontro Nacional de Ensino de Química, 18., 2016, Florianópolis. Anais... Florianópolis: ENEQ, 2016. Disponível em:

http://www.eneq2016.ufsc.br/anais/resumos/R1019-3.pdf. Acesso em: 19 jul. 2020.

RAMOS, L. C.; SILVA, J. L. P. B. Modelo quântico do átomo: uma análise do ensino nas noções de quantum de uma grandeza e comportamento dual da energia e da matéria. In: Encontro Nacional de Ensino de Química, 16.; Encontro de Educação Química da Bahia, 10., 2012, Salvador. Anais... Salvador: ENEQ/ EDUQUI, 2012. Disponível em: http://www.eneq2012.qui.ufba.br/modulos/submissao/Upload/43124.pdf. Acesso em: 19 jul. 2020.

REIS, Rafaela S.; LEITE, Bruno S.; LEÃO, Marcelo B. C. Apropriação das Tecnologias da Informação e Comunicação no ensino de ciências: uma revisão sistemática da última década (2007-2016). Revista Novas Tecnologias na Educação, Porto Alegre, v. 15, n. 2, 2017. Disponível em: https://seer.ufrgs.br/renote/article/view/79232/46123. Acesso em: 19 jul. 2020.

ROZENTALSKI, E. F.; PORTO, P. A. O conceito de orbital em livros didáticos de química geral para o Ensino Superior no século XX. In: Encontro Nacional de Ensino de 
Química, 16; Encontro de Educação Química da Bahia, 10, 2012, Salvador. Anais.... Salvador: ENEQ/ EDUQUI, 2012. Disponível em:

http://www.eneq2012.qui.ufba.br/modulos/submissao/Upload/43077.pdf. Acesso em: 19 jul. 2020.

SILVA, J. C.; SILVA, J. L. P. B. Sobre o ensino de números quânticos. In: Encontro Nacional de Ensino de Química, 17, 2014, Ouro Preto. Anais... Ouro Preto: ENEQ, 2014. p. 1326-1334. Disponível em: http://www.sbq.org.br/ensino/ eneq. Acesso em: 19 jul. 2020.

SILVA, J. C.; SILVA, J. L. P. B. O sistema conceitual dos números quânticos. In: Encontro Nacional de Ensino de Química, 18, 2016, Florianópolis. Anais... Florianópolis: ENEQ, 2016. Disponível em: http://www.eneq2016.ufsc.br/anais/resumos/R0204-1.pdf. Acesso em: 19 jul. 2020.

SILVA, J. L. P. B.; CUNHA, M. B. de M. Para compreender o modelo atômico quântico. In: Encontro Nacional de Ensino de Química, 14, 2008, Curitiba. Anais... Curitiba: ENEQ, 2008. Disponível em:

http://www.quimica.ufpr.br/eduquim/eneq2008/resumos/R0298-1.pdf. Acesso em: 19 jul. 2020.

SUART JÚNIOR, J. B.; ZULIANI, S. R. Q. A.; CARNEIRO, M. C. O Que é a Incerteza? Reflexões sobre o Ensino e Aprendizagem de Conceitos, no Desenvolvimento de uma Estratégia de Ensino. In: Encontro Nacional de Ensino de Química, 14, 2008, Curitiba. Anais... Curitiba: ENEQ, 2008. Disponível em: http://www.quimica.ufpr.br/eduquim/eneq2008/resumos/R0813-1.pdf. Acesso em: 19 jul. 2020.

SUART JÚNIOR, J. B.; ZULIANI, S. R. Q. A.; CARNEIRO, M. C. Descrição Física da Realidade e o Princípio de Incerteza: livros didáticos e vieses filosóficos. In: Encontro Nacional de Ensino de Química, 15., 2010, Brasília. Anais... Brasília: ENEQ, 2010. Disponível em: http://www.sbq.org.br/eneq/xv/resumos/R0550-1.pdf. Acesso em: 19 jul. 2020.

SUART JÚNIOR, J. B.; ZULIANI, S. R. Q. A.; CARNEIRO, M. C. Dicotomias epistemológicas e representações: a Física a Química e a Teoria Quântica. In: Encontro Nacional de Ensino de Química, 16.; Encontro de Educação Química da Bahia, 10., 2012, Salvador. Anais... Salvador: ENEQ/ EDUQUI, 2012. Disponível em: http://www.eneq2012.qui.ufba.br/modulos/submissao/Upload/41661.pdf. Acesso em 19 jul. 2020.

TEIXEIRA, P. V. N. R.; MILLANI, W.; YUNES, S. F. Alunos Aprendendo com Alunos: Uma Experiência para Introdução à Química Quântica. In: Encontro Nacional de Ensino de Química, 15., 2010, Brasília. Anais... Brasília: ENEQ, 2010. Disponível em: http://www.sbq.org.br/eneq/xv/resumos/R1203-1.pdf. Acesso em: 19 jul. 2020. 